\title{
The effects of budesonide on angiogenesis in a murine asthma model
}

Yan Sun', Jinrong Wang', Huabing Li², Lifeng Sun', Yulin Wang', Xiuzhen Han ${ }^{1}$

${ }^{1}$ Department of Pediatrics, Provincial Hospital Affiliated to Shandong University, Jinan, China

2Department of Pediatrics, Zhucheng People's Hospital, Zhucheng, Shandong, China

Submitted: 20 June 2011

Accepted: 15 October 2011

Arch Med Sci 2013; 9, 2: 361-367

DOI: $10.5114 /$ aoms.2013.33194

Copyright $\odot 2013$ Termedia \& Banach

\begin{abstract}
Introduction: The aim of this study is to determine the effects and mechanisms of budesonide on angiogenesis in a murine asthma model.

Material and methods: Murine asthma models were established and mice were divided into three groups: the model group (OVA-sensitized and challenged mice), the BUD group (budesonide-treated mice) and the PBS group (normal control mice). Mice in the BUD group were administered with inhaled budesonide $(100 \mu \mathrm{g} / \mathrm{kg})$ daily. The effects on airway inflammation, angiogenesis, expression of hypoxia inducible factor-1 $\alpha$ (HIF-1 $\alpha$ ) and vascular endothelial growth factor (VEGF) were examined.

Results: Administration of budesonide ameliorated allergic airway inflammation $(2.90 \pm 0.18$ vs. $4.80 \pm 0.20, p<0.01)$ and significantly reduced the percentage vascularity $(0.78 \pm 0.14$ vs. $2.83 \pm 0.90, p<0.01)$ compared with those in the asthmatic model mice. It also reduced the expression of HIF- $1 \alpha$ (immunohistochemistry results: $71.70 \pm 1.40$ vs. $89.60 \pm 0.79, p<0.001$; western blotting results: $0.88 \pm 0.41$ vs. 0.97 $\pm 0.47, p<0.05$ ), as well as that of VEGF (immunohistochemistry results: $26.30 \pm 1.03$ vs. $93.30 \pm 1.54, p<0.001$; western blotting results: $1.12 \pm 0.22$ vs. $2.08 \pm 0.30, p<0.01$ ). Percentage vascularity had positive correlation with both HIF-1 $\alpha(r=0.785, p<0.01)$ and VEGF $(r=0.693, p<0.01)$ expression. Furthermore, there is positive relationship between HIF-1 $\alpha$ and VEGF expression $(r=0.641, p<0.05)$.

Conclusions: The results demonstrate that budesonide has an important inhibitory effect on angiogenesis in asthma. Inhaled administration of budesonide achieved anti-angiogenic activity through inhibition of HIF- $1 \alpha$ and VEGF expression. The results support a potential anti-remodeling role for budesonide in the treatment of human asthma.
\end{abstract}

Key words: angiogenesis, budesonide, asthma, hypoxia inducible factor-1 $\alpha$, vascular endothelial growth factor.

\section{Introduction}

Airway inflammation, airway remodeling and hyperresponsiveness are the fundamental components of pathogenesis that lead to symptoms and lung function changes in asthma [1, 2], which are often accompanied by formation of new blood vessels (angiogenesis). Vessel number and size, vascular surface area and vascular leakage are all increased in biopsies from patients with asthma. These contribute to the airway obstruction or airway hyper-responsiveness, or both [3]. Common medications used to treat asthma are glucocorticoids, leukotriene receptor antagonists and theophylline [4]. And corticosteroids are the most effective drugs to suppress

\section{Corresponding author:} Prof. Xiuzhen Han Department of Pediatrics Provincial Hospital Affiliated to Shandong University 324 Jingwu Road Jinan, China, 250021 Phone: 8653186886366 Fax: 8653187068707 E-mail: sunyan6150@126.com 
airway inflammation, mainly by reducing proinflammatory cytokines [5-7]. In addition, corticosteroids seem to reverse asthma-induced airway remodeling, including the increased vascularity of the bronchial wall [8], partly through regulating target genes to suppress the vascular elements of angiogenesis [9]. Despite the complex actions of inflammatory mediators on vascular endothelial and smooth muscle cells, the mechanisms of inhaled corticosteroids to inhibit angiogenesis have not been completely clarified. Since disease severity in asthma seems to correlate with airway vascularity, the molecular mechanism of inhaled corticosteroid may be of important value.

Previous studies demonstrate that vascular endothelial growth factor (VEGF) plays a key role in the formation of the initial vascular plexus and mediates the process of angiogenesis [10]. Vascular endothelial growth factor is suggested to be a possible mediator in the anti-angiogenic effect of budesonide, while the nuclear transcription factor which regulates VEGF expression in angiogenesis is to be investigated. Recently, VEGF was found to be mediated by hypoxia inducible factor- $1 \alpha$ (HIF- $1 \alpha$ ) in asthmatic patients [11]. Hypoxia inducible factor- $1 \alpha$ is a heterodimeric basic-helix-loop-helix-PAS domain transcription factor that mediates gene expression in response to changes of oxygen concentration [12-14]. Injection of mice with a constitutively active form of HIF- $1 \alpha$ was sufficient to induce angiogenesis of nonischemic tissue in vivo, which suggests that HIF-1 $\alpha$ plays a role in angiogenesis. In our study, we decided to assess the effects and molecular mechanisms of budesonide on angiogenesis in asthma. The changes of airway inflammation and percentage vascularity were examined, and the relationships between angiogenesis and HIF- $1 \alpha$ and VEGF expression were tested. Moreover, we elucidated the effects of budesonide on HIF-1 $\alpha$ and VEGF expression.

\section{Material and methods}

\section{Animals}

Female BALB/C mice (6-8 weeks old, $n=30$ ) were purchased from the animal experiments center of Shandong University. They were housed under conditions of constant temperature (about $23^{\circ} \mathrm{C}$ ) and a $12 \mathrm{~h}$ light/dark cycle, and given free access to food and water. All animal experiments conducted in this study were in accordance with the Guide for the Care and Use of Laboratory Animals.

\section{OVA-induced asthma in mice}

Most studies on asthma mechanisms use a single allergen challenge model [15], OVA-induced asthma was widely used as described: mice were sensitized by an injection $(200 \mu \mathrm{l}$ i.p.) of $100 \mu \mathrm{g}$ chicken ovalbumin (OVA, Sigma) emulsified in aluminum hydroxide $(1 \mathrm{mg})$ on days 1 and 14 . From day
21, mice were challenged with $2 \%$ OVA twice a week via a nebula (Bestneb Nebuliier) in the experimental chambers. Mice were divided into three groups randomly and treated differently $(n=10)$. In the OVA group: murine models of asthma were sensitized and challenged with OVA twice a week as stated. In the BUD group: OVA-sensitized and challenged mice were administered with inhaled budesonide $(100 \mu \mathrm{g} / \mathrm{kg})$ daily from day 28 , an hour before OVA challenge via the nebula. In the PBS group: normal control mice were sensitized and challenged with the placebo of phosphate-buffered saline (PBS).

Challenged for 12 weeks, mice of three groups were anesthetized with $1 \%$ pentobarbital sodium (30 mg/kg i.p.). Lungs were saved for histological examination.

\section{Histological analysis}

Lungs were inflated with $4 \%$ paraformaldehyde, processed in paraffin-embedded blocks. Five- $\mu \mathrm{m} \mathrm{sec-}$ tions were stained with hematoxylin and eosin. Images were scanned on the microscope (Leica, DM4000B) with the software (Leica IM 50 Image Manager). The degree of peribronchial inflammation was assessed according to the following histological grading system: (1) absence of peribronchial inflammatory cells, (2) a few scattered peribronchial inflammatory cells involving less than $25 \%$ of the circumference of the bronchus, (3) focal peribronchial inflammatory cell infiltrate not completely surrounding a bronchus (i.e., involving approximately $25-75 \%$ of the circumference of the bronchus), (4) one definite layer of peribronchial inflammatory cells completely surrounding a bronchus, (5) 2 definite layers of peribronchial inflammatory cells completely surrounding a bronchus, and (6) 3 or more layers of peribronchial inflammatory cells completely surrounding a bronchus. In each lung section the mean peribronchial inflammatory index was calculated by adding the index values of all the individual bronchioles in the lung section and dividing the index by the number of bronchioles present in the lung section [16].

\section{VEGF and HIF- $1 \alpha$ expression and percentage vascularity by immunohistochemistry}

Paraffin sections of lung were deparaffinized, dehydrated, and exposed to $3 \% \mathrm{H}_{2} \mathrm{O}_{2}$ for 15 min to inhibit endogenous peroxidase. After boiling in sodium citrate $(0.01 \mathrm{~mol} / \mathrm{l}, \mathrm{pH} 6.0)$ for antigen retrieval to unmask antigen epitopes and blocking with $3 \%$ bovine serum albumin, sections were incubated with primary antibodies to von Willebrand factor (vWF) (Gene Tech), VEGF and HIF-1 $\alpha$ (Santa Cruz, $1: 200$ ) overnight at $4^{\circ} \mathrm{C}$ respectively. Biotinylated secondary antibodies were used and detected by $S A B C$ Elite kit reagents, followed by incubation with diaminobenzidine. 
Vasculature was labeled with antibody to VWF that binds uniformly to the surface of endothelial cells. All subsequent steps were performed on a ZSGB-BIO Autostainer. A random HPF (200X) was selected, and the VWF-positive area was divided by the total area of the image field, which yielded the percentage vascularity (\%). The scale of quantification for VEGF was calculated as the percentage of immunostaining bronchial epithelial cells (\%). HIF-1 expression was calculated as the percentage of immunostaining alveolar epithelial cells (\%).

\section{Measurement of VEGF and HIF-1 $\alpha$ expression by Western blotting}

Lung tissue was homogenized in the presence of protease inhibitors to obtain extract of lung protein. The concentration was determined using BCA-100 protein quantitative analysis kit (Shenergy Biocolor BioScience\&Technology Company). For Western blotting analysis, an equal amount of protein $(30 \mu \mathrm{g})$ from each group was loaded on an SDS-polyacrylamide gel, then transferred to nitrocellulose membrane. The membrane was blocked with 5\% nonfat milk in Tris-buffered saline Tween 20 (25 mM Tris pH 7.5, $150 \mathrm{mM} \mathrm{NaCl}$, and 0.1\% Tween 20) for $1 \mathrm{~h}$, and incubated with primary anti-VEGF or anti-HIF-1 antibody overnight at $4^{\circ} \mathrm{C}$, then hybridized with the secondary antibody (Dako, $1: 2000)$. Specific binding was revealed by enhanced chemilumi- nescence (Santa Cruz Biotechnology). For the loading control, the membrane was incubated with anti$\beta$-actin (1 : 1000, ABcam Biotechnology). X-ray film was scanned with a computer-assisted densitometer to quantify band optical density (Alphalmager 2200). The relative ratios of VEGF or HIF-1 $\alpha$ level to $\beta$-actin level were calculated.

\section{Statistical analysis}

The results were expressed as mean \pm SEM and compared between groups by one-way ANOVA with subsequent post hoc test or Mann-Whitney test dependent on distribution of data. The correlation of VEGF and HIF-1 $\alpha$ expression ratios with percentage vascularity were evaluated by Spearman's test. A value of $p$ of less than 0.05 was considered statistically significant.

\section{Results}

\section{Budesonide ameliorates allergic airway inflammation}

Histological analysis revealed typical pathological features of asthma in the OVA group (Figure 1). Numerous inflammatory cells infiltrated around the bronchioles, accompanied with bronchial epithelial injury. The inflammation index was increased significantly in the OVA group compared with that in the PBS group ( $4.80 \pm 0.20$ vs. $1.60 \pm 0.16, p<0.01)$.
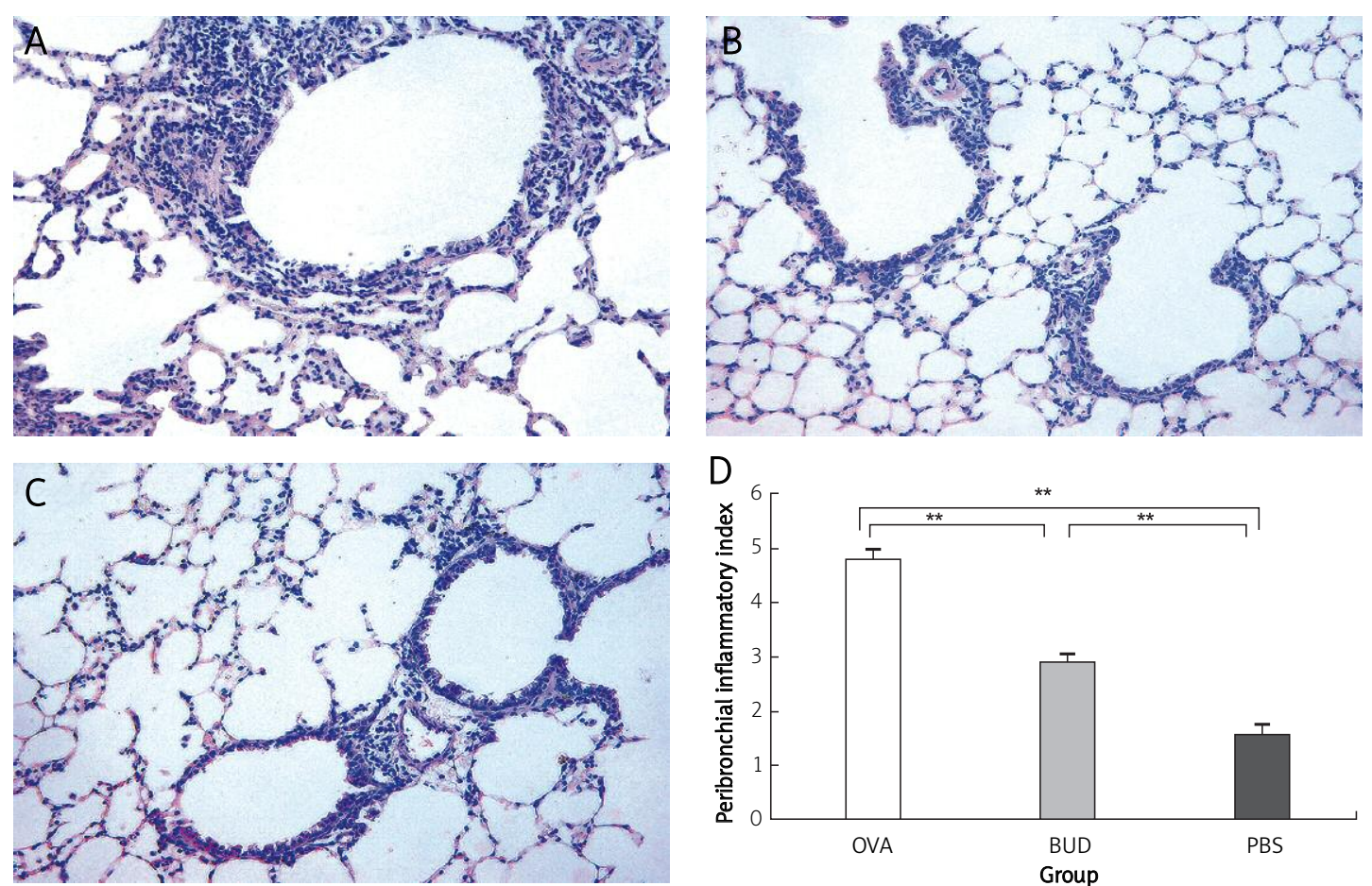

Figure 1. Histopathological sections from lung tissue of mice. Typical pathological features of asthma were revealed in the OVA group, numerous inflammatory cells infiltrated and epithelial injuries were also found. The inflammation index was increased significantly compared with that in the PBS group. Administration of budesonide markedly reduced the inflammation index compared with that in the OVA group. A - OVA group, B - BUD group, C - PBS group, D - inflammation indexes of each group. Magnification is $200 \times$

Data are shown as mean $\pm S E M ;{ }^{* *} p<0.01$ 
Administration of budesonide markedly ameliorated airway inflammation, inflammatory cells were reduced and bronchial epithelial injury was to a lesser extent. There was a significant difference of the inflammation index between the BUD group and the OVA group ( $2.90 \pm 0.18$ vs. $4.80 \pm 0.20, p<0.01)$.

\section{Budesonide reduces angiogenesis}

Vessels sprouted after OVA challenge (Figure 2). Percentage vascularity was increased significantly in the OVA group compared with that in the PBS group ( $2.83 \pm 0.90$ vs. $0.42 \pm 0.10, p<0.001)$, and was decreased greatly after administration of budesonide. There was a significant difference of percentage vascularity between the BUD group and the OVA group (0.78 \pm 0.14 vs. $2.83 \pm 0.90, p<0.01)$.

\section{Budesonide reduces VEGF expression}

VEGF expression was significantly increased in the OVA group, expressed in bronchial epithelial cells, and also in the alveolar epithelial cells and endothelia (OVA group $93.30 \pm 1.54$ PBS group 23.10 $\pm 2.81, p<0.001)$. Also budesonide greatly reduced VEGF level (BUD group $26.30 \pm 1.03$ vs. OVA group $93.30 \pm 1.54, p<0.001)$, nearly to the normal level of the PBS group (BUD group $26.30 \pm 1.03$ vs. PBS group $23.10 \pm 2.81, p>0.05)$. Consistent with the results of immunohistochemistry (Figure 3), the relative ratio of VEGF to $\beta$-actin level by Western blotting (Figure 4) revealed that VEGF expression was increased significantly in the OVA group compared

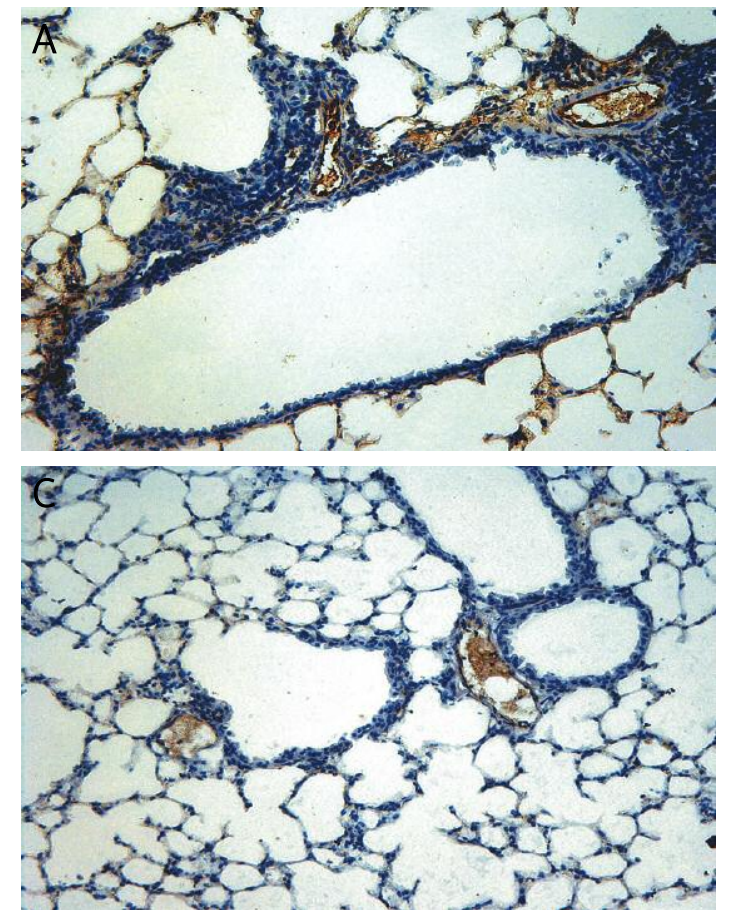
compared with that in the PBS group, and was reduced in the BUD group. A - OVA group, B - BUD group, $C-P B S$ group, $D$ - percentage of vascularity. Magnification is $200 \times$ Data are shown as mean \pm SEM. ${ }^{*} p<0.05,{ }^{* *} p<0.01$, ${ }^{* *} p<0.001$

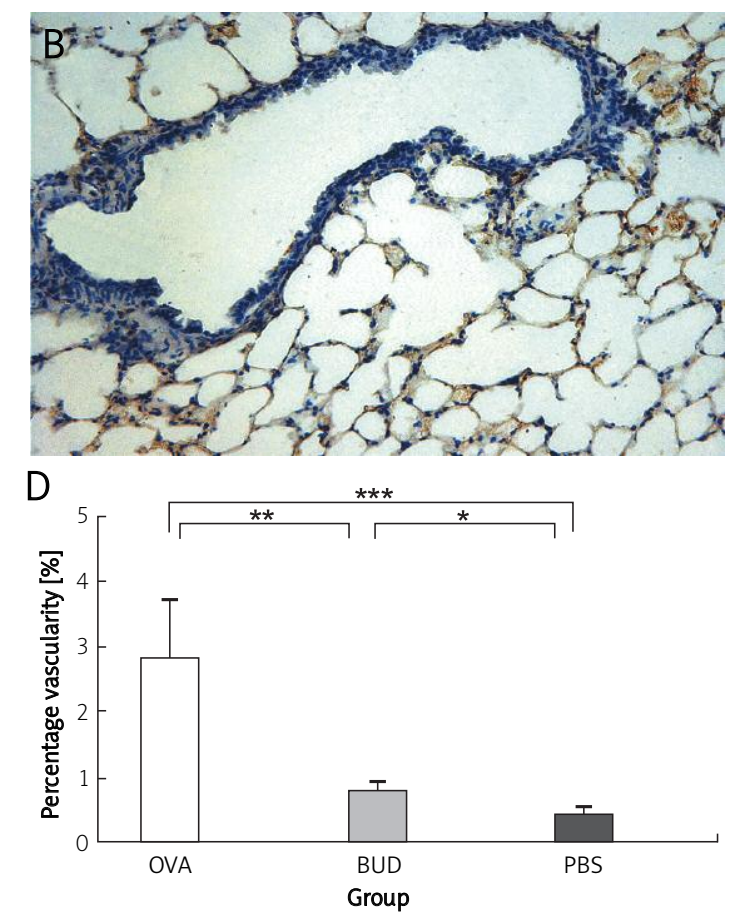

with that of the PBS group $(2.08 \pm 0.30$ vs. 0.96 $\pm 0.30, p<0.01$ ), and was decreased after administration of budesonide compared with that in the OVA group (1.12 \pm 0.22 vs. $0.08 \pm 0.30, p<0.01)$. There was no difference between the BUD group and the PBS group (1.12 \pm 0.22 vs. $0.96 \pm 0.30, p>0.05)$.

\section{Budesonide reduces HIF-1 $\alpha$ expression}

To further clarify the anti-angiogenic mechanism of budesonide, we measured HIF-1 $\alpha$ level in lung tissue. In the normal mice of the PBS group, only a few HIF-1 $\alpha$ positive cells were tested, while HIF-1 $\alpha$ expression was markedly increased in the nuclei of alveolar epithelia of the OVA group (OVA group $89.60 \pm 0.79$ vs. PBS group $11.70 \pm 0.30, p<0.001$ ). Also budesonide greatly reduced HIF- $1 \alpha$ level (BUD group $71.70 \pm 1.40$ vs. OVA group $89.60 \pm 0.79$, $p<0.001)$. Consistent with the results of immunohistochemistry (Figure 5), the relative ratio of HIF-1 $\alpha$ to $\beta$-actin level by Western blotting (Figure 4) revealed that HIF-1 $\alpha$ expression was significantly upregulated in the OVA group compared with that in the PBS group $(0.97 \pm 0.47$ vs. $0.32 \pm 0.12, p<0.01)$ and was downregulated in the BUD group com pared with that in the OVA group $(0.88 \pm 0.41 \mathrm{vs}$. $0.97 \pm 0.47, p<0.05)$.

\section{Correlation of VEGF and HIF-1 $\alpha$ expression with percentage vascularity}

Percentage vascularity had a significant positive correlation with VEGF expression $(r=0.693, p<0.01)$, 

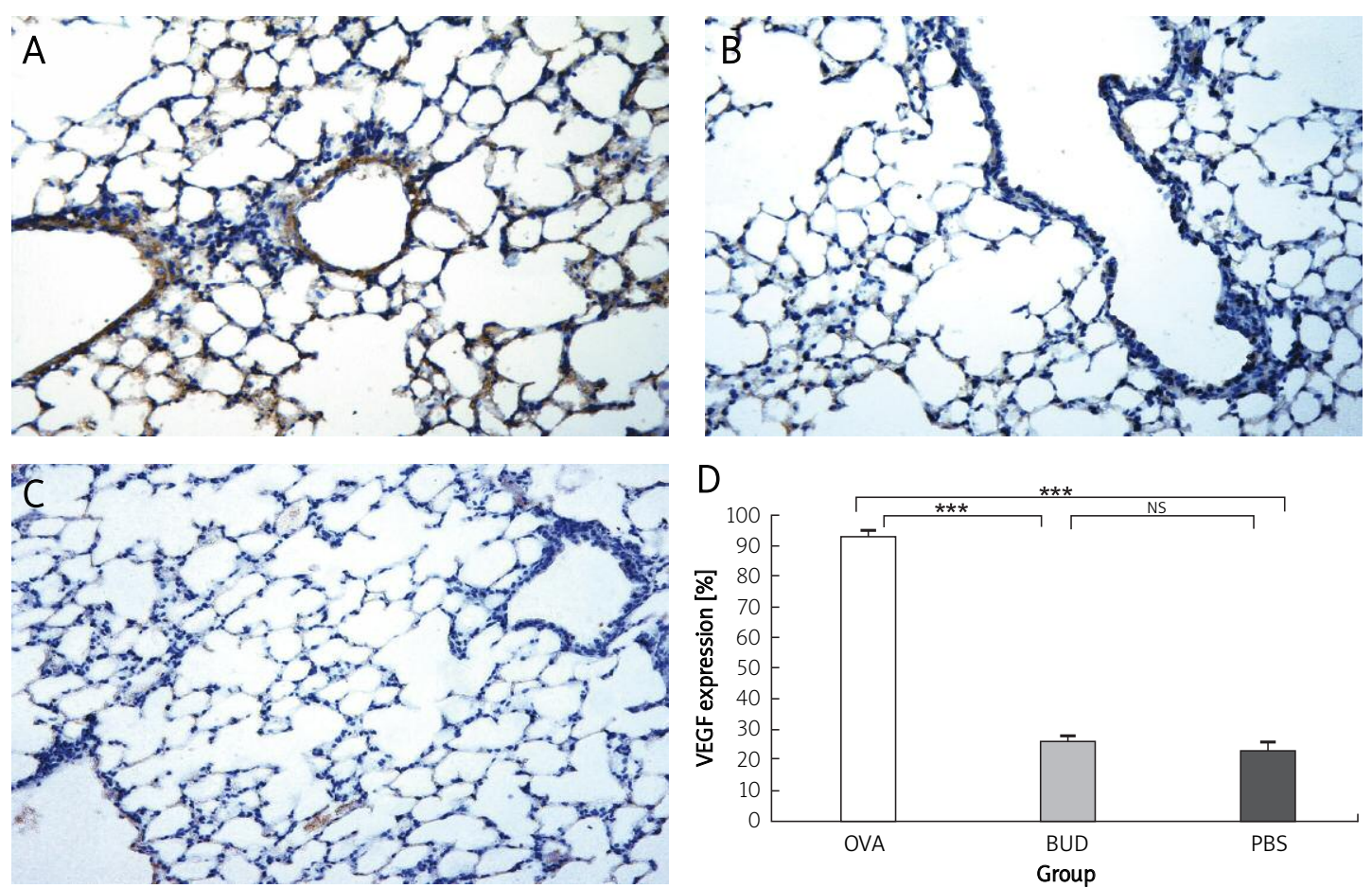

Figure 3. VEGF expression in lung tissue of mice. VEGF expression was increased in the OVA group compared with that in the PBS group, and reduced in the BUD group. A - OVA group, B - BUD group, C-PBS group, D - percentage of immunostaining bronchial epithelial cells. Magnification is 200x

Data are shown as mean \pm SEM. ${ }^{* * *} p<0.001$. NS - not statistically significant

A
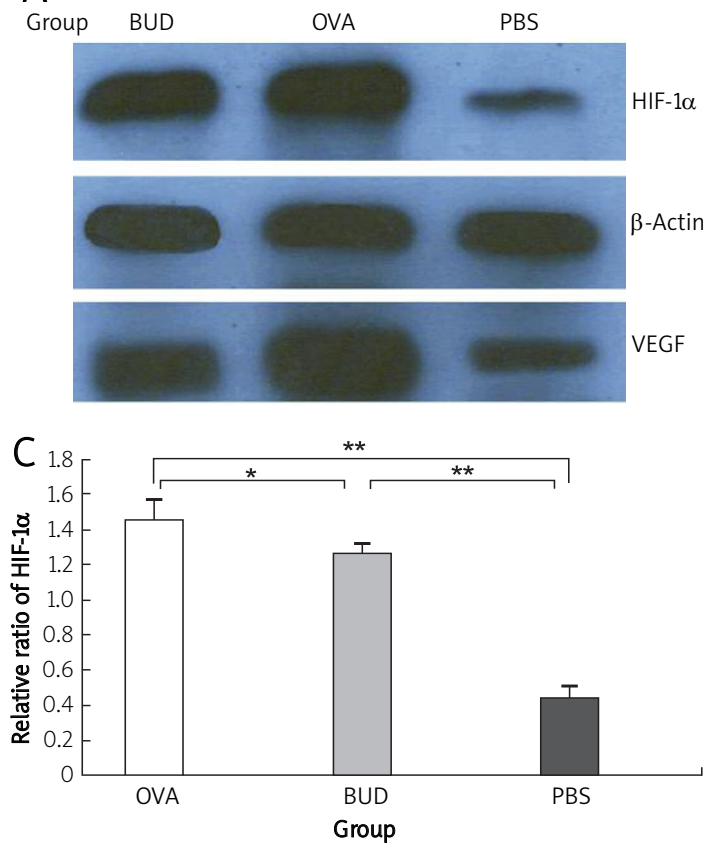

also with HIF-1 $\alpha$ expression $(r=0.785, p<0.01)$ by Western blotting. Furthermore, there was significant positive relationship between HIF-1 $\alpha$ and VEGF expression $(r=0.641, p<0.05)$.

\section{Discussion}

To investigate the effect of budesonide on angiogenesis in asthma, we examined the influx of in-

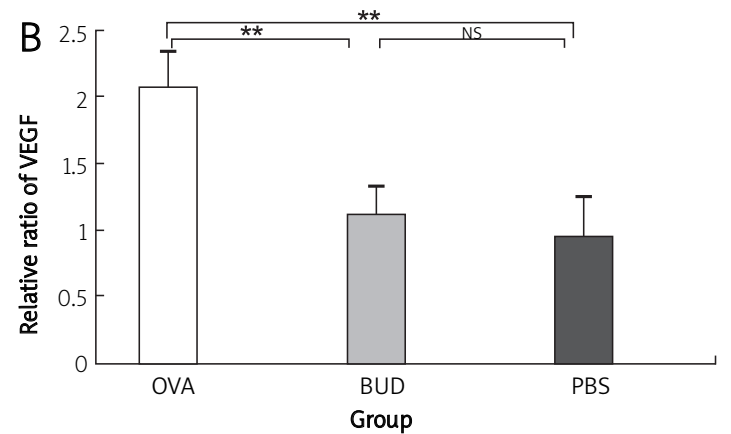

Figure 4. VEGF and HIF-1 expression by Western blotting. Consistent with the results of immunohistochemistry, the relative ratios of VEGF and HIF-1 $\alpha$ to $\beta$-actin level revealed that both were significantly upregulated in the OVA group compared with those in the PBS group, and were downregulated in the BUD group. $\mathrm{A}-\mathrm{X}$-ray film by Western blotting, $\mathrm{B}$ - relative ratio of VEGF to $\beta$-actin, $\mathrm{C}$ - relative ratio of HIF-1 $\alpha$ to $\beta$-actin

Data are shown as mean \pm SEM. ${ }^{*} p<0.05,{ }^{* *} p<0.01$. NS - not statistically significant

flammatory cells and changes of percentage vascularity. In the lung tissue of murine asthma models, numerous inflammatory cells infiltrated around the bronchioles, and bronchial epithelial injuries were also found. Infection is an important trigger of exacerbation of bronchial asthma [17]. Effector cells of inflammation (lung mast cells, basophils, eosinophils, macrophages, etc.) may be the major sources 

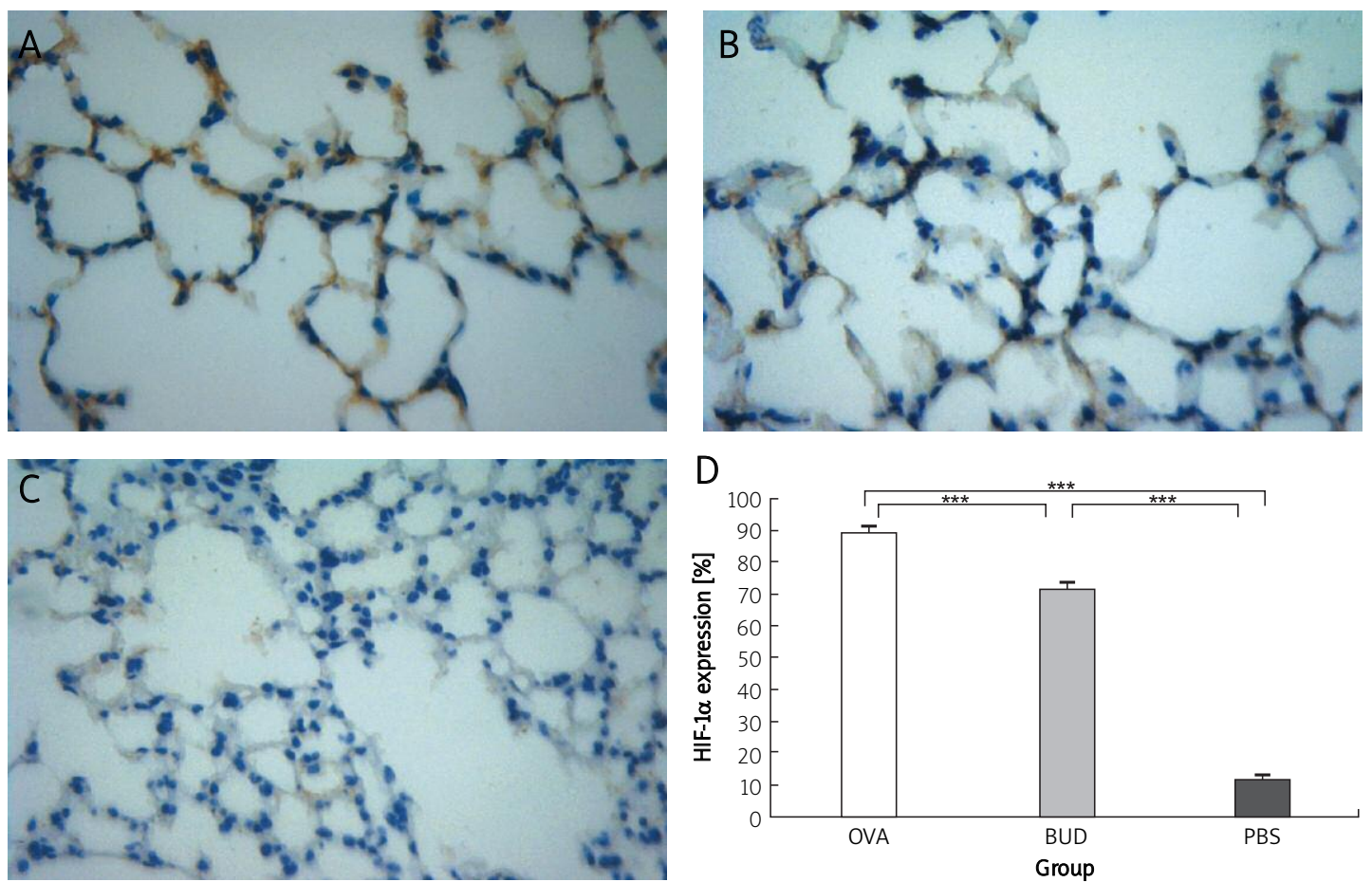

Figure 5. HIF-1 $1 \alpha$ expression in lung tissue of mice. HIF-1 $\alpha$ expression was upregulated in the OVA group, mostly expressed in the nuclei of alveolar epithelium, and was reduced in the BUD group. A - OVA group, B - BUD group, C - PBS group, D - percentage of immunostaining alveolar epithelial cells. Magnification is 400x

${ }^{* * *} p<0.001$

of a vast array of angiogenic factors. Corresponding with the reports that bronchial vascularity was increased in patients with asthma [18-20], percentage vascularity was increased significantly in murine models of asthma. And administration of budesonide not only ameliorated the airway inflammation, but also significantly reduced the vascularity in our study. The findings confirm that budesonide has an anti-angiogenic effect in asthma.

In murine asthma models, VEGF expression was increased in bronchial epithelial cells, alveolar epithelial cells and vascular endothelia. The VEGF expression was elucidated to be positively correlated with percentage vascularity. As known, VEGF has a critical role in the initial vascular plexus and the process of angiogenesis [21, 22]. And budesonide markedly reduced VEGF expression in our study; thus the functions of increasing proliferation of endothelial cells, promoting angiogenesis and vascular maturation were inhibited, finally reducing the percentage vascularity in the BUD group. Decreased VEGF level was suggested to be an explanation for the anti-angiogenic effect of budesonide.

The regulatory factor of VEGF remains to be elucidated. In our study, a positive correlation between HIF- $1 \alpha$ and VEGF was demonstrated in asthma. Recent studies showed that activation of VEGF was mediated by HIF-1 in androgen-sensitive tumors [23], and further inhibition of HIF-1 using siRNA introduction or chemical inhibition suppressed VEGF induction in TCL1 cells [24]. These confirmed the
HIF-1 - hypoxia response element (HRE) - VEGF signaling cascade [25]. In the hypoxia condition of asthma, HIF-1 $\alpha$ expression is increased and eventually acts as a master regulator of numerous hypoxia-inducible genes. HIF-1 $\alpha$ level was positively correlated with percentage vascularity. The angiogenic effect of HIF-1 $\alpha$ was also confirmed in the report that injection of mice with a constitutively active form of HIF-1 was sufficient to induce angiogenesis of nonischemic tissue in vivo [26]. Furthermore, a key role of HIF-1 in angiogenesis has been revealed using allele HIF-1-knockout mice, which developed impaired pulmonary vascular remodeling when subjected to chronic hypoxia [27]. As the oxygen regulator subunit, HIF-1 $\alpha$ determines HIF-1 activity. The positive correlation of HIF-1 $\alpha$ with both percentage vascularity and VEGF in our study indicates hypoxia-induced angiogenesis as a result of the increased expression of HIF-1 $\alpha$ and its important target gene VEGF. When hypoxia was ameliorated after administration of budesonide, both VEGF and HIF-1 $\alpha$ expression were reduced, airway inflammation was inhibited, and vascularity was also reduced with the downregulation of these angiogenic factors. While the inhibitory effect of budesonide on HIF-1 $\alpha$ was apparently weaker than that on VEGF, other mechanisms to reduce VEGF might be involved. A recent study demonstrated that the inhibitory effect of budesonide on VEGF expression was suppressed by mifepristone (RU 486), a glucocorticoid receptor antagonist, suggesting that bude- 
sonide reduces VEGF expression partly through its glucocorticoid receptor-mediated action [28].

Taken together, we demonstrate that budesonide inhibits airway angiogenesis in asthma, and also significantly reduces VEGF and HIF-1 $\alpha$ expression. Both VEGF and HIF-1 $\alpha$ play key roles in angiogenesis and VEGF is the important target gene of HIF-1 $\alpha$. The anti-angiogenic effect of budesonide was presumably through the down-regulation of HIF-1 $\alpha$ and VEGF expression. As one of the widely used conventional agents of inhalational corticosteroids [29], budesonide reduces angiogenic factor expression and vascularity, and thus modulates airway remodeling in asthma. These results support a potential anti-remodeling role for budesonide in the treatment of human asthma.

In conclusion, these results demonstrate that budesonide has an important inhibitory effect on angiogenesis in asthma. Inhaled administration of budesonide achieved anti-angiogenic activity through inhibition of HIF and VEGF expression. The results support a potential anti-remodeling role for budesonide in the treatment of human asthma.

\section{References}

1. Royce SG, Tang ML. The effects of current therapies on airway remodeling in asthma and new possibilities for treatment and prevention.Curr Mol Pharmacol 2009; 2: 169-81.

2. Żukiewicz-Sobczak W, Krasowska E, Zwoliński J, et al. Allergic diseases - current state of knowledge. Postep Derm Alergol 2012; 29: 451-5.

3. Detoraki A, Granata F, Staibano S, Rossi FW, Marone G, Genovese A. Angiogenesis and lymphangiogenesis in bronchial asthma. Allergy 2010; 65: 946-58.

4. Radwan ZM, Yamamah GA, Shaaban HH, Abdel-Rahman AM, Ismaeil AA, Mostafa EM. Effect of different monotherapies on serum nitric oxide and pulmonary functions in children with mild persistent asthma. Arch Med Sci 2010; 6: 919-25.

5. De Bosscher K, Vanden Berghe W, Haegeman G. The interplay between the glucocorticoid receptor and nuclear factor-kappaB or activator protein-1: molecular mechanisms for gene repression. Endocr Rev 2003; 24: 488-522.

6. Adcock IM, Ito K, Barnes PJ.Glucocorticoid: effects on gene transcription. Proc Am Thorac Soc 2004; 1: 247-54.

7. Oleś D, Szczepankiewicz A, Wołuń-Cholewa M, et al. Does concentration influence viability of the bronchial epithelial cell line chronically exposed to antiasthmatic drugs? Postep Derm Alergol 2012; 29: 363-8.

8. Chanez P, Bourdin A, Vachier I, Godard P, Bousquet J, Vignola AM. Effects of inhaled corticosteroids on pathology in asthma and chronic obstructive pulmonary disease. Proc Am Thorac Soc 2004; 1: 184-90.

9. Horvath G, Wanner A. Inhaled corticosteroids: effects on the airway vasculature in bronchial asthma. Eur Respir J 2006; 27: 172-87.

10. Baluk P, Lee CG, Link H, et al. Regulated angiogenesis and vascular regression in mice overexpressing vascular endothelial growth factor in airways. Am J Pathol 2004; 165: 1071-85.

11. Lee SY, Kwon S, Kim KH, et al. Expression of vascular endothelial growth factor and hypoxia-inducible factor in the airway of asthmatic patients. Ann Allergy Asthma Immunol 2006; 97: 794-9.

12. Jaakkola P, Mole DR, Tian YM, et al. Targeting of HIF-alpha to the von Hippel-Lindau ubiquitylation complex by O2-regulated prolyl hydroxylation. Science 2001; 292: 468-72.

13. Kaelin WG Jr. How oxygen makes its presence felt. Genes Dev 2002; 16: 1441-5.

14. Ivan $\mathrm{M}$, Kondo $\mathrm{K}$, Yang $\mathrm{H}$, et al. HIFalpha targeted for VHLmediated destruction by proline hydroxylation: implications for 02 sensing. Science 2001; 292: 464-8.

15. Lan F, Liu K, Zhang J, Qi Y, Li K, Lin P. Th17 response is augmented in OVA-induced asthmatic mice exposed to HDM. Med Sci Monit 2011; 17: 132-8.

16. Cho JY, Miller M, Baek KJ, et al. Immunostimulatory DNA sequences inhibit respiratory syncytial viral load, airway inflammation, and mucus secretion. J Allergy Clin Immunol 2001; 108: 697-702.

17. Fukushima C, Matsuse H, Fukahori S, et al. Aspergillus fumigatus synergistically enhances mite-induced allergic airway inflammation. Med Sci Monit 2010; 16: 197-202.

18. Hoshino M, Aoike N, Takahashi M, Nakamura Y, Nakagawa T. Increased immunoreactivity of stromal cell-derived factor1 and angiogenesis in asthma. Eur Respir J 2003; 21: 804-9.

19. Salvato G. Quantitative and morphological analysis of the vascular bed in bronchial biopsy specimens from asthmatic and non-asthmatic subjects. Thorax 2001; 56: 902-6.

20. Tanaka H, Yamada G, Saikai T, et al. Increased airway vascularity in newly diagnosed asthma using a high-magnification bronchovideoscope. Am J Respir Crit Care Med 2003; 168: 1495-9.

21. Yuksel H, Kose C, Yilmaz O, et al. Increased expression of tissue vascular endothelial growth factor and foetal liver kinase-1 receptor in seasonal allergic rhinitis and relevance to asthma component. Clin Exp Allergy 2007; 37: 1183-8.

22. Feltis BN, Wignarajah D, Zheng L, et al. Increased vascular endothelial growth factor and receptors: relationship to angiogenesis in asthma. Am J Respir Crit Care Med 2006; 173: 1201-7.

23. Boddy JL, Fox SB, Han C, et al. The androgen receptor is significantly associated with vascular endothelial growth factor and hypoxia sensing via hypoxia-inducible factors HIF-1a, HIF-2a, and the prolyl hydroxylases in human prostate cancer. Clin Cancer Res 2005; 11: 7658-63.

24. Fukushima K, Murata M, Hachisuga M, et al. Hypoxia inducible factor 1 alpha regulates matrigel-induced endovascular differentiation under normoxia in a human extravillous trophoblast cell line. Placenta 2008; 29: 324-31.

25. Tsuzuki Y, Fukumura D, Oosthuyse B, Koike C, Carmeliet $P$, Jain RK. Vascular endothelial growth factor (VEGF) modulation by targeting hypoxia-inducible factor-1alpha $\rightarrow$ hypoxia response element $\rightarrow$ VEGF cascade differentially regulates vascular response and growth rate in tumors. Cancer Res 2000; 60: 6248-52.

26. Kelly BD, Hackett SF, Hirota K, et al. Cell type-specific regulation of angiogenic growth factor gene expression and induction of angiogenesis in nonischemic tissue by a constitutively active form of hypoxia-inducible factor 1 . Circ Res 2003; 93: 1074-81.

27. Yu AY, Shimoda LA, lyer NV, et al. Impaired physiological responses to chronic hypoxia in mice partially deficient for hypoxia-inducible factor 1alpha. J Clin Invest 1999; 103: 691-6.

28. Bandi N, Kompella UB. Budesonide reduces vascular endothelial growth factor secretion and expression in airway (Calu-1) and alveolar (A549) epithelial cells. Eur J Pharmacol 2001; 425: 109-16.

29. Mathew J, Aronow WS, Chandy D. Therapeutic options for severe asthma. Arch Med Sci 2012; 8: 589-97. 